\title{
VALPARAÍSO DE GOIÁS: A FORMAÇÃO DE UM MUNICÍPIO DE MIGRANTES NO CONTEXTO DO DISTRITO FEDERAL*
}

\author{
VALPARAÍSO DE GOIÁS: THE FORMATION OF A CITY OF MIGRANT IN THE \\ CONTEXT OF THE DISTRITO FEDERAL
}

\author{
VALPARAÍSO DE GOIÁS: LA FORMACIÓN DE UNA CIUDAD DE MIGRANTES \\ EN EL CONTEXTO DEL DISTRITO FEDERAL
}

\author{
Eguimar Felício Chaveiro - Universidade Federal de Goiás - Goiânia - Goiás - Brasil \\ eguimar@hotmail.com \\ Gilmar Elias Rodrigues da Silva - Universidade Federal de Goiás - Goiânia - Goiás - Brasil \\ gilmarelias@hotmail.com
}

\begin{abstract}
Resumo
Este artigo propõe analisar a formação do município de Valparaíso de Goiás (G0). Recorremos ao estudo da cidade como um processo dinâmico, incluindo a sua posição, função e importância no Entorno Sul do Distrito Federal. Averiguaremos as transformações socioespaciais advindas do processo de segregação que Brasília impõe aos trabalhadores. 0 problema principal do trabalho é: qual a dinâmica socioespacial de Valparaíso de Goiás, município formado por migrantes, a reboque da fragmentação territorial de Brasília? Ao levantar trabalhos de dissertações, teses, artigos, documentações; gerar dados mediante trabalho de campo e organizar tabelas a partir de informações de censos e anais, descobriu-se que o município em questão é hoje um dos mais populosos e de maior densidade populacional em uma das menores áreas territoriais com ausência de zona rural do Entorno de Brasília e do estado de Goiás. Essa condição demonstra que o seu estudo torna-se importante para conhecer a realidade do município, bem como as suas particularidades e ligação com outras escalas.

Palavras-chave: Valparaíso de Goiás, migração, dinâmica socioespacial, fragmentação territorial.
\end{abstract}

\section{Abstract}

This paper proposes analysis the formation of the municipality of Valparaíso of Goiás-GO. We choose the study of the city as a dynamic process, included his position, function and importance on the south of the Distrito Federal. We will investigate the sociospatial transformations resulting from the segregation process that Brasilia imposes to the workers. The mainly problem of the job is: which is the sociospatial dynamic of the municipality like Valparaíso of Goiás formed by migrant because the territorial fragmentation of Brasília? To the raising research work, particularly dissertations, thesis, articles, investigation documentation, generate data through field work and organizing tables of information from the Census and annals; we found that the municipality at issue it is now one of the most populous and the bigger density population in one of the smaller territorial areas with absence of rural zone surroundings of Brasilia and the state of Goiás. This condition demonstrates that the study of this municipality became important to understand the reality from this city council, and its peculiarities and its connection with other scales.

Keywords: Valparaíso de Goiás, migration, sociospatial dynamics, territorial fragmentation.

\section{Resumen}

En este artículo se pretende analizar la formación de la municipalidad de Valparaíso de Goiás-GO. Recurrí al estudio de la ciudad como un proceso dinámico, incluyendo su posición, su función y importancia en los

\footnotetext{
* Pesquisa financiada pela Capes, por meio de concessão de bolsa de mestrado.
} 
alrededores del sur del Distrito Federal. Nosotros vamos a investigar las transformaciones socios espaciales resultantes del proceso de segregación que Brasilia impone a los trabajadores. El problema principal de este trabajo es: ¿cuál es la dinámica socio espacial de una ciudad cómo Valparaíso de Goiás formado por los migrantes con la fragmentación territorial de Brasilia? Al plantear el trabajo de investigación, especialmente disertación, tesis, artículos, documentación de la investigación, generar datos a través del trabajo de campo y la organización de tablilla de información del Censo y anales, se descubrió que el municipio en cuestión es ahora uno de los municipios mas populosos y tiene la mayor densidad poblacional en una de las áreas territoriales más pequeñas, sin una zonal rural en el entorno de Brasilia y el estado de Goiás. Esta condición indica que su estudio es importante para conocer la realidad de la región en que se encuentra el municipio, y su particularidad y su relación con otras escalas.

Palabras clave: Valparaíso de Goiás, migración, dinámica socioespacial, fragmentación territorial.

Introdução

Os estudos geográficos que incidem sobre as problemáticas dos espaços e dos territórios contemporâneos têm revelado que, de fato, o modelo de acumulação vigente dará um caráter singular a todas as escalas espaciais. No caso específico de Goiás, no que concerne à estrutura e à dinâmica dos municípios, isso parece verdadeiro, pois os denominados municípios pequenos, especialmente os da faixa norte, perdem população, apresentam Índice de Desenvolvimento Humano (IDH) bastante desigual e mostram a sua pouca capacidade de gerar renda local e produzir autonomia financeira.

Os municípios do entorno das metrópoles - Goiânia e Brasília apresentam um crescimento vertiginoso e tornam-se guaridas de migrantes que, a partir da divisão regional do trabalho, ganham especificidades e dinâmicas próprias em razão dessa realidade: servir como arena de reserva de mão de obra para abastecer essas metrópoles terciárias.

O município de Valparaíso de Goiás, mais que se enquadrar nessa realidade por pertencer ao Entorno do Distrito Federal, tem uma especificidade espacial: a sua origem é protagonizada pela fragmentação de territórios de antigos municípios, como no caso de Luziânia, e pelo crescimento de Brasília, por meio de afluxos de migrantes que, interessados em produzir a sua existência na capital federal, foram obrigados a deslocar-se para o seu Entorno.

A interescalaridade de Valparaíso de Goiás exige uma atenção: os migrantes que formaram o município e que até hoje radicam nele, especificamente na zona urbana, uma vez que não há zona rural, possuem relações institucionais com Goiás e relações sociais com Brasília. Essa interescalaridade redunda numa ambiguidade territorial que, por sua vez, 
culmina na construção da identidade territorial de Valparaíso de Goiás, pulverizada recorrentemente pela cultura dos sempre chegantes.

Ora, ao referir-se a Valparaíso de Goiás, deve-se considerar que se trata de um município eminentemente formado por migrantes, com uma área territorial de $60,111 \mathrm{~km}^{2}$ que abriga uma população de 132.947 habitantes (IBGE, 2010), o primeiro no estado de Goiás em densidade demográfica e do qual cerca de $46 \%$ da população ativa trabalha e/ou estuda em Brasília.

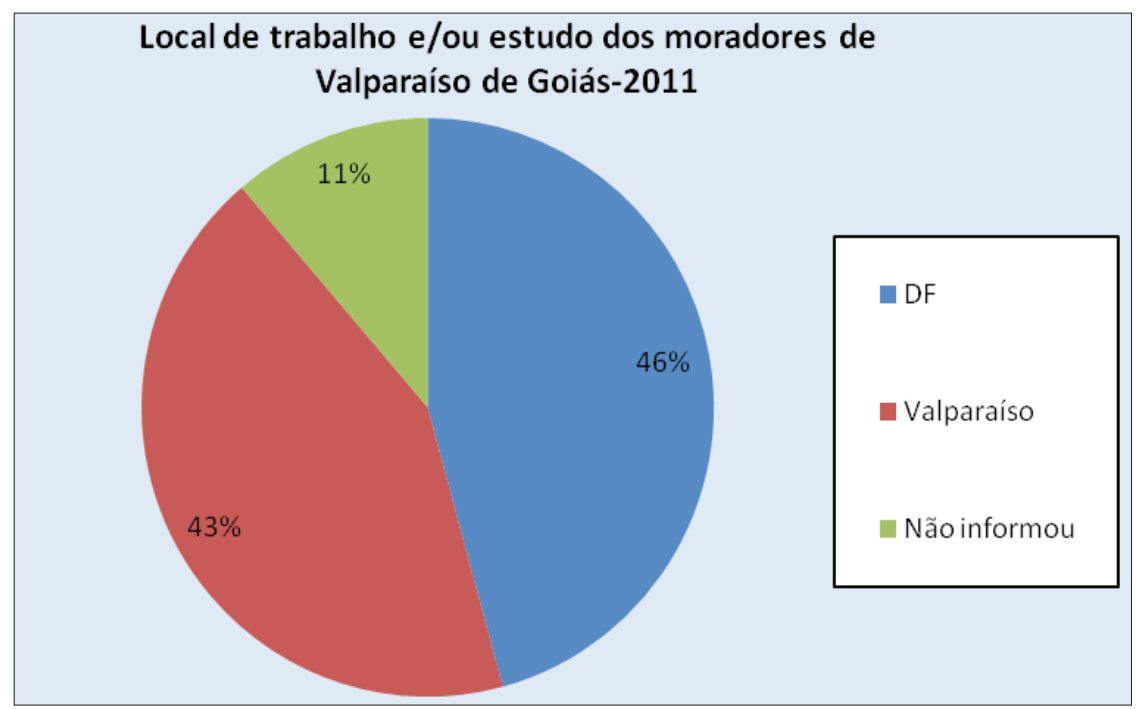

FIGURA 1- Local de trabalho e/ou de estudo dos moradores de Valparaíso de Goiás em 2011

Fonte: Elaborada por Gilmar Elias Rodrigues da Silva (2012).

Esta constatação induz a ponderar o seguinte: uma realidade espacial profundamente fluida como é o caso de Valparaíso de Goiás, em que as pessoas não possuem vínculos históricos com o lugar, tal como ocorre em outras realidades, desdobra-se no modo como os sujeitos veem a sua relação com o município. Pode-se dizer, então, que a fragmentação territorial não é um dado apenas do arranjo espacial, mas que entranha a vida dos sujeitos e seu dispositivo para significar a vida no lugar, muitas vezes repelindo-o. 
Ao tomar como referência a participação direta da migração na constituição de Valparaíso de Goiás e em sua dinâmica socioespacial, propõe-se que o ato de migrar, mais que compor os quadros estatísticos daquela realidade espacial, torna-se determinante nas relações políticas, culturais e subjetivas.

A formação de Valparaíso de Goiás: a gênese de um município formado por migrantes

A atual configuração do território do município de Valparaíso de Goiás, situado na Microrregião do Entorno do Distrito Federal, conforme demonstra o mapa que se segue (Figura 2), deve ser entendida a partir do momento em que os problemas da urbanização brasileira no Planalto Central se intensificam, advindos da interiorização da capital federal.

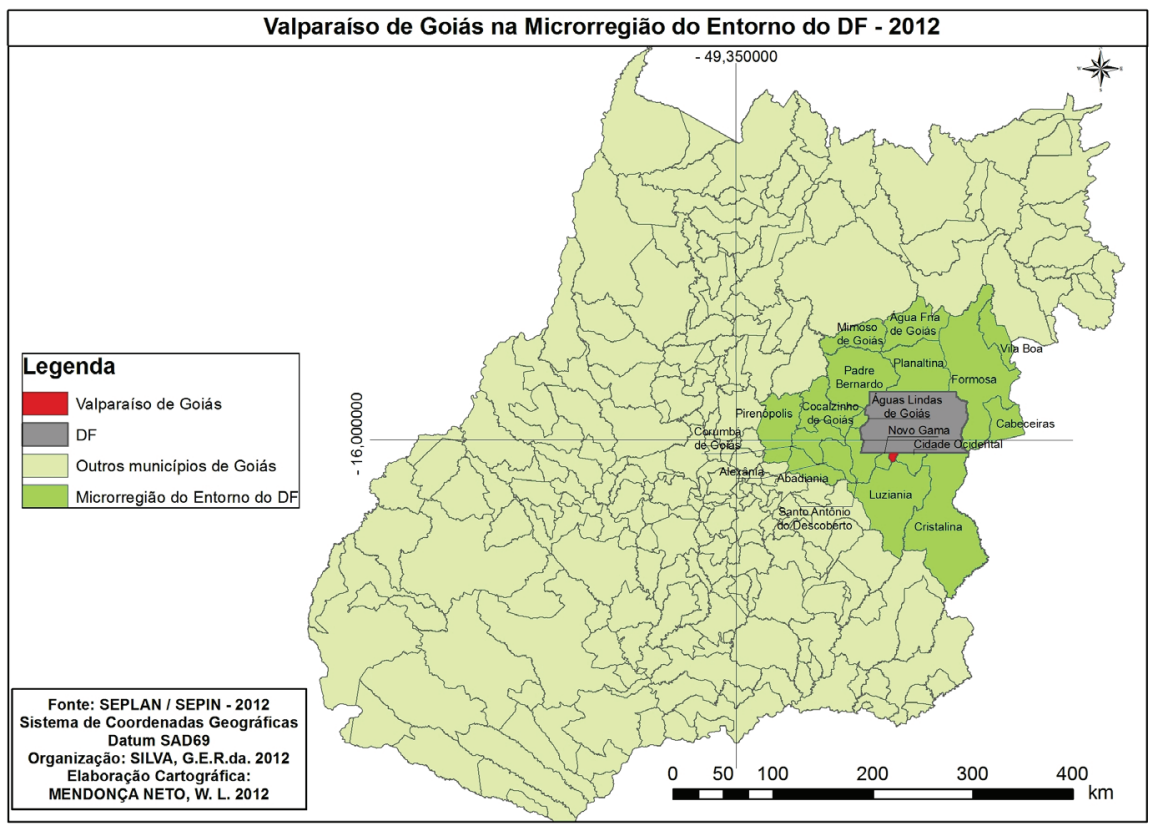

FIGURA 2 - Valparaíso de Goiás na Microrregião do Entorno do DF, 2012 Fonte: Seplan/Sepin (2012).

Org.: Gilmar Elias Rodrigues da Silva (2012).

Elaboração: Wilson L. Mendonça Neto (2012). 
"Com a redescoberta do cerrado em Goiás" (Santos, 2009, p. 69) e como solução ao impasse de trabalhadores que ao chegar a Brasília não conseguem se estabelecer, por causa da carestia imobiliária, do controle do solo pelo Estado, da segregação socioespacial e da pressão por moradia nos municípios vizinhos ao quadrilátero do Distrito Federal, surge Valparaíso de Goiás. Os loteadores reproduziram aí o "modelo" de urbanização polinucleada da capital, em núcleos esparsos no território de antigas fazendas de Goiás (Paviani, 1987), dando início a um forte movimento migratório rumo ao referido município.

Reis, no ano de 1975, publicou em um encarte imobiliário de Luziânia um texto acerca dos impactos advindos da construção da nova capital federal. O autor assevera que "a construção de Brasília sacolejou a vida rotineira de nosso povo. [...] Por sua vez, núcleos urbanos apareceram, de um dia para outro", estabelecendo assim evidências de novas territorialidades no Planalto Central brasileiro, que contribuíram para o surgimento de vários aglomerados urbanos no território goiano e nas adjacências do DF.

No município de Luziânia, nas proximidades com a fronteira do DF, surgiram: Cidade Ocidental (emancipada em 1991), Novo Gama e Valparaíso de Goiás (ambos emancipados em 1995). Tal fato deve ser considerado para a compreensão da relação de interdependência histórica do município em estudo com o Distrito Federal, no contexto da formação territorial do país.

Embora o registro dos primeiros conjuntos habitacionais instalados oficialmente no território onde hoje se localiza Valparaíso de Goiás ocorra entre os anos de 1979-1980, desde fins da década de 1950 já existiam na região algumas residências nas adjacências da rodovia planejada Brasília-Belo Horizonte (BR-040), nas proximidades da divisa de Goiás com o Distrito Federal. Os estudos de Barreira (2009) apontam que

o incremento da migração, ocorrida, sobretudo nas décadas de 1960 e 1970 no Distrito Federal, a política de assentamento das famílias de baixa renda implementada pelo Governo do Distrito Federal (GDF) nas cidades satélites não foi suficiente para contemplar a todos, restando aos não atendidos pelos programas sociais, como opção de moradia, apenas o chamado entorno.

Em decorrência do processo explicado pela autora, Valparaíso de Goiás surge como alternativa à pressão por moradia exercida a partir da 
construção de Brasília. E nas décadas seguintes à consolidação, só restou aos excluídos do DF migrar para os municípios goianos mais próximos à capital. Por isso, torna-se relevante ressaltar a ação do Estado, perceptível e presente no contexto da (re)configuração da dinâmica do território e dos atores sociais, pois, ao mesmo tempo que promove ações para o assentamento de famílias de baixa renda, cria a segregação delas na capital da república, contribuindo para a criação da periferia. Santos (2009, p. 123124), em vista de processos semelhantes pondera:

Programas de atendimento à população de baixa renda que somente foram desenvolvidos a partir do final da década de 70, através do Banco Nacional de Habitação (BNH), com o dinheiro público, vêm contribuir e agravar a tendência ao espraiamento das cidades e para estimular a especulação imobiliária na mesma.

Valparaíso de Goiás, dentro do contexto expresso nas palavras de Santos (2009), foi considerado por especuladores imobiliários como ideal, por já apresentar algumas vantagens para o investimento, como área de relevo relativamente plano, com eletrificação rural e, sobretudo, por sua localização nas proximidades da BR-040, que orientou e orienta a urbanização e a mobilidade até o Plano Piloto de Brasília.

\section{A participação de Brasília na formação de Valparaíso de Goiás}

Os estudos de população apontam, ao tomarem o território goiano como foco, que há um crescimento populacional desigual, concentrado e disperso, conforme a estrutura de redes organizadas em manchas (Chaveiro; Calaça, 2008). Dito de outra forma, pode-se afirmar que existem quatro grandes legendas demográficas em Goiás: a região norte, que apresenta menor crescimento; a faixa meridional, que possui crescimento médio; os municípios pequenos, que perdem população; e os municípios das regiões metropolitanas, que crescem aceleradamente, notadamente no entorno das metrópoles Goiânia e Brasília.

O fato de Valparaíso de Goiás, dentre os municípios do Entorno, ser o mais próximo de Brasília, distante aproximadamente $35 \mathrm{~km}$ do Plano Piloto, faz com ele sirva de atrativo para a especulação imobiliária e, consequentemente, para a moradia do migrante que não consegue se estabelecer no Distrito Federal. Brasília é, portanto, ao mesmo tempo, o centro de atração de migrantes de outras regiões do país e convergência para a 
migração como também o centro de expulsão deles para os municípios de seu Entorno.

A Tabela 1 apresenta dados comprobatórios do movimento de migrantes que, chegando a Brasília, não conseguem aí permanecer e vão em direção às cidades de seu Entorno. Nesse processo de "espraiamento", o Entorno Sul - composto pelos municípios ao sul do DF: Cidade Ocidental, Cristalina, Luziânia, Novo Gama e Valparaíso de Goiás - é uma das regiões que recebem o maior número de migrantes, dada a sua proximidade com o Distrito Federal.

TABELA 2 - Perfil dos migrantes do Entorno do DF - 2005

\begin{tabular}{|l|c|c|c|c|c|}
\hline \multirow{2}{*}{\multicolumn{1}{c|}{ Cidade }} & \multicolumn{5}{c|}{ Residência Anterior } \\
\cline { 2 - 6 } & BA & MG & RJ & SP & DF \\
\hline Água Fria & $11,2 \%$ & $7,2 \%$ & $0,4 \%$ & $1,7 \%$ & $34 \%$ \\
\hline Águas Lindas de GO & $4,2 \%$ & $2,1 \%$ & $0,3 \%$ & $1,4 \%$ & $75,9 \%$ \\
\hline Cidade Ocidental & $5,7 \%$ & $3,4 \%$ & $1,5 \%$ & $2,7 \%$ & $62,7 \%$ \\
\hline Luziânia & $5,8 \%$ & $6,7 \%$ & $0,5 \%$ & $1,8 \%$ & $56,8 \%$ \\
\hline Novo Gama & $4,8 \%$ & $3,7 \%$ & $0,6 \%$ & $1,6 \%$ & $60,1 \%$ \\
\hline Padre Bernardo & $4,2 \%$ & $4,9 \%$ & $0,0 \%$ & $0,7 \%$ & $72,4 \%$ \\
\hline Planaltina de GO & $8,3 \%$ & $5,2 \%$ & $0,3 \%$ & $1,7 \%$ & $56,2 \%$ \\
\hline Sto A. Descoberto $^{\text {to }}$ Valparaíso de GO & $5,4 \%$ & $3,9 \%$ & $0,6 \%$ & $1,9 \%$ & $57,5 \%$ \\
\hline Total & $5,6 \%$ & $5,1 \%$ & $2,1 \%$ & $1,9 \%$ & $56,5 \%$ \\
\hline
\end{tabular}

Conclui-se, como demonstra o quadro, que Brasília é um lugar de passagem para o migrante, ou seja, é um Trampolim Demográfico, pois na formação da população que constitui os municípios do Entorno do DF verifica-se um elevado percentual vindo da capital, que embora mantenham nesta seus postos de trabalho, educação e outros equipamentos, é nesses municípios que fixam moradias.

Em decorrência da fixação das pessoas na região do Entorno Sul, assiste-se à formação de um corredor de povoamento que vai de Brasília a Luziânia, estabelecido às margens da rodovia BR-040. Esse eixo caracteriza-se por um intenso movimento de pessoas e veículos num espaço intraurbano que dinamiza as paisagens, dando-lhes um caráter conurbado e conflituoso. 
O fenômeno de novas expansões que se agregam entre Brasília e Valparaíso de Goiás pode ser evidenciado ao observarem-se as fronteiras da cidade goiana de Valparaíso de Goiás e as "cidades satélites" de Santa Maria e Gama (DF), confirmando o que nos estudos da geografia urbana conceitua-se como "cidade conjugada funcionalmente". Cristalina, de todas as cidades do Entorno Sul, embora fazendo fronteira com o $\mathrm{DF}$, é aquela que menos impacto sofre com essa migração. Tal se explica pelo fato de o referido município ter a sua sede mais distante do centro atrativo, que é Brasília, e por possuir estruturas inibidoras de urbanização na área fronteiriça GO/DF (Paviani; Gouvêa, 2003; Arrais, 2007). Por conseguinte, a dinâmica que se desdobrou do processo acarretou diversos problemas socioespaciais, cristalizados nas carências de equipamentos urbanos coletivos, como educação, segurança, saúde e transporte.

Acerca das desigualdades socioespaciais, Carlos (2011) assevera que a desigualdade espacial é produto da desigualdade social. Assim sendo, pode-se inferir que a interiorização da capital federal estimulou o crescimento da desigualdade espacial no Entorno, ao impedir que a leva de trabalhadores que migraram para a sua edificação não tivesse condições de usufruir a infraestrutura da capital nas décadas seguintes.

Esse processo persistiu ao término da construção da nova capital federal. Esses trabalhadores não foram absorvidos pelo mercado de trabalho e muito menos conquistaram condições de permanência na capital. Tornaram-se sujeitos indesejados, sendo exilados para a periferia, dentro do quadrilátero para as "cidades satélites"; ao chegarem a estas foram novamente expulsos para além da fronteira de seu território, reforçando a tendência anteriormente observada e concretizando o quadro de desigualdade social.

Os territórios nos quais os trabalhadores se fixam, embora sejam acessíveis e de "fácil" mobilidade em relação ao Distrito Federal, não oferecem condições mínimas de infraestrutura, denotando uma falta de investimentos públicos, bem como causando um rápido inchaço populacional nos diferentes municípios, o que pode ser constatado no gráfico a seguir (Figura 3), que tem por referência o crescimento populacional de Valparaíso de Goiás entre os anos de 1980-2010.

Pode-se averiguar pelo gráfico que em alguns períodos e em curtos espaços de tempo, por exemplo, entre 1980 e 1985, a população mais que dobrou, cresceu num percentual de 157,51\%; no período de 1987 a 1990, o 
crescimento populacional foi de $89,55 \%$. Outro exemplo pode ser constatado entre os anos de 1991 e 1996, quando em apenas cinco anos a população saltou de 52.500 habitantes para 75.380, crescendo 43,58\%. Além dos citados percentuais, podem ser percebidos ainda, na Figura 3, períodos de curto intervalo de tempo com acentuado crescimento populacional.

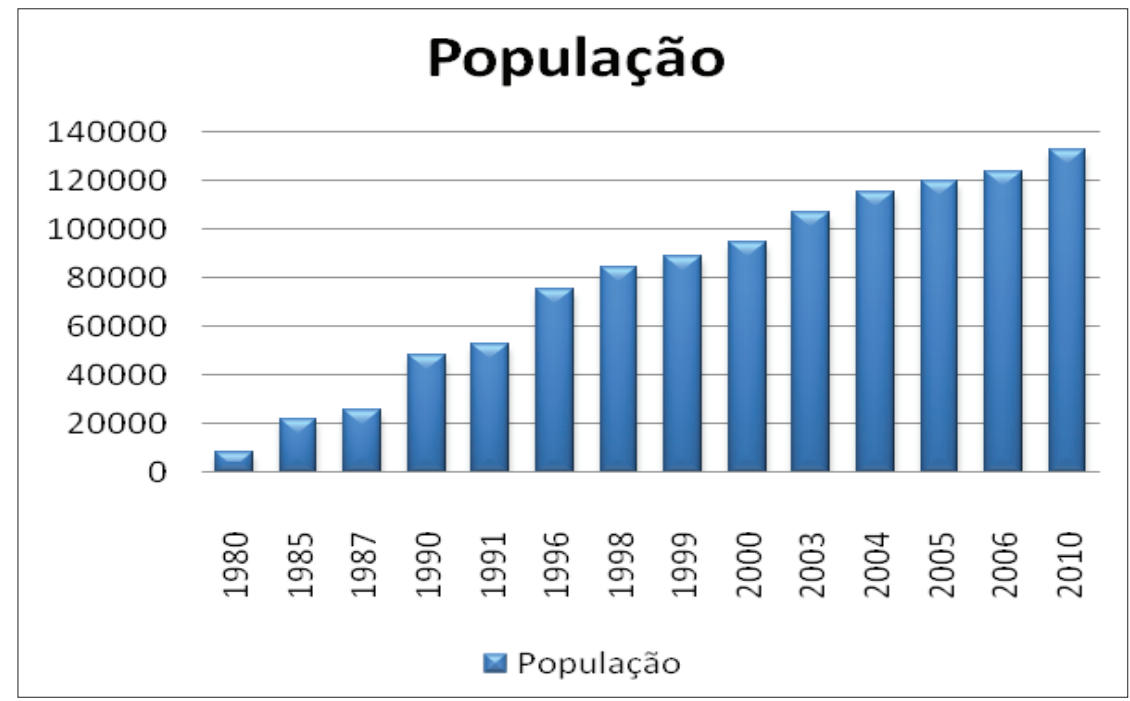

FIGURA 3 - Crescimento populacional de Valparaíso de Goiás 1980-2010.

Fonte: IBGE - Acervo de Luziânia/2011.

Elaboração: Gilmar Elias Rodrigues da Silva (2011).

O mapa a seguir (Figura 4) traz outras contribuições acerca da constituição populacional dos municípios goianos da Microrregião do Entorno do Distrito Federal, dentre eles Valparaíso de Goiás. Nota-se que o processo de fragmentação dos municípios nas adjacências do DF é resultado do fenômeno migratório em direção a eles, o que pode ser verificado na população residente, no que diz respeito aos naturais e aos não naturais.

Em Valparaíso de Goiás, tal processo é percebido. O município encontra-se com mais de $83 \%$ de seus moradores não naturais, o que comprova que as observações alhures asseguram ser o município formado por migrantes e que grande percentual de seus moradores exerce a migração diária para trabalho e/ou estudo no Distrito Federal. 


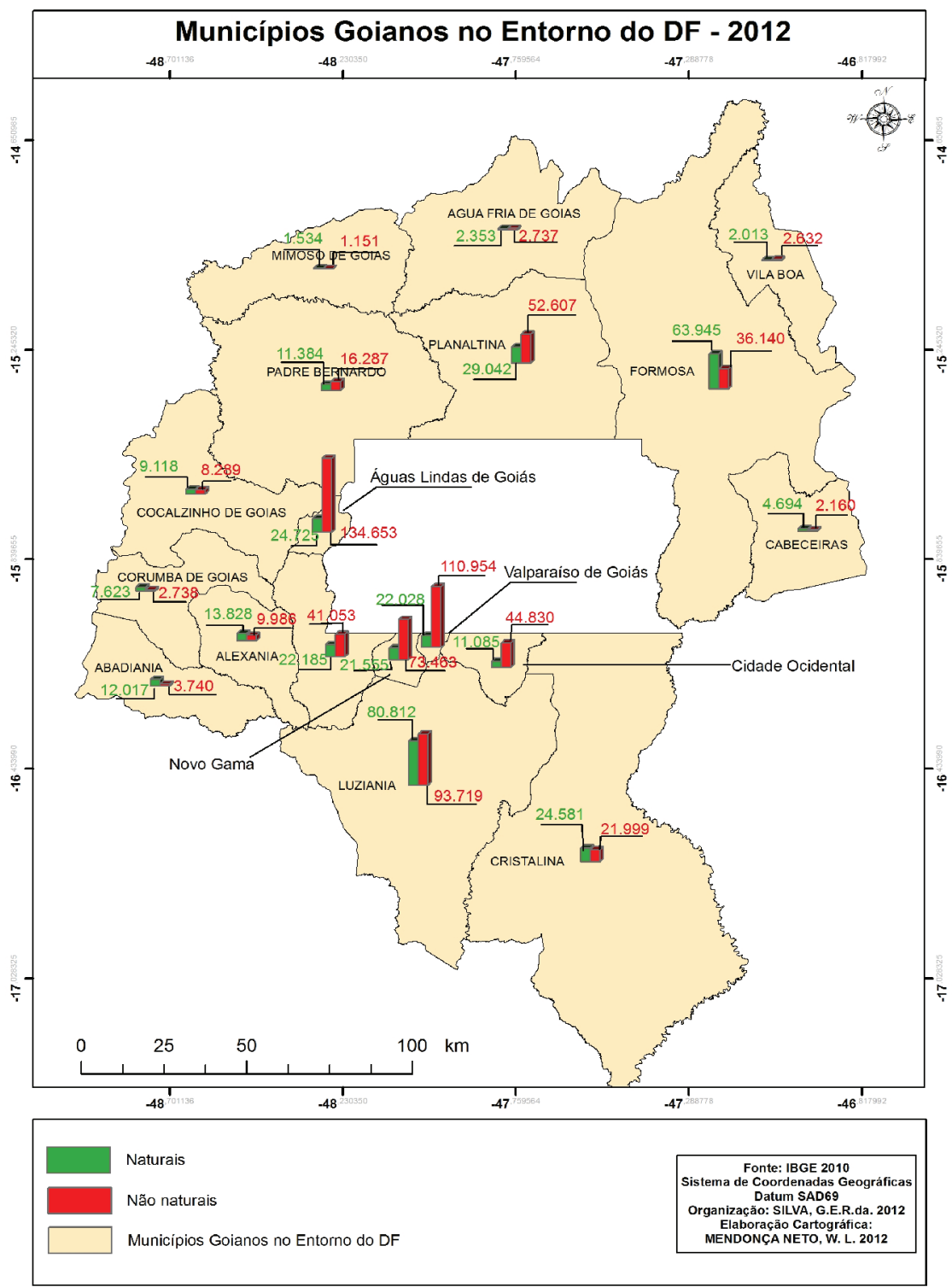

FIGURA 4 - Valparaíso de Goiás na Microrregião do DF: naturais e não naturais - 2012 Fonte: IBGE (2010).

Org.: Gilmar Elias Rodrigues da Silva (2012).

Elaboração: Wilson L. Mendonça Neto (2012). 
O processo migratório produz e reproduz conflitos nos municípios do Entorno do DF. O intenso fluxo de migrantes cria situações adversas no que concerne à identidade local e regional, na medida que desorganiza relações historicamente estabelecidas e desagrega valores que auxiliam na identificação e na distinção do "eu", do "outro" e do "nós" no tempo e no espaço.

\section{Considerações finais}

O presente trabalho discutiu o processo de formação do município de Valparaíso de Goiás, que se concretizou não pela expansão urbana do município ao qual pertencia - Luziânia - antes de sua emancipação política em 1995, e sim pelo resultado da migração e pelo processo de segregação socioespacial que se efetivou na construção e consolidação da capital federal.

O desenvolvimento urbano de Brasília nas décadas seguintes continuou "empurrando" os trabalhadores para a periferia além do limites do DF, numa espécie de Trampolim Demográfico, embora esses trabalhadores mantenham vínculos sociais diretos com Brasília.

Neste contexto, os municípios que constituíram a região do Entorno do DF, com destaque para o município de Luziânia, "sofreram" uma desintegração referente às relações e aos nexos que articulam o modelo socioespacial desse território. Vimos que o que ocorreu de fato com a implantação da capital foi uma fragmentação territorial por parte dos municípios da região do Entorno do DF.

Brasília, a partir da nova lógica espacial passou, então, a definir as ações socioespaciais de seu Entorno, como também a arquitetar as novas formas espaciais, o que acabou originando a (re)configuração da região e determinando as singularidades dos municípios do Entorno, como no caso de Valparaíso de Goiás.

Essa situação levou o referido município a se constituir em um território com ausência de zona rural, detentor de uma das menores áreas territoriais do estado de Goiás, bem como de uma das mais elevadas densidades populacionais. Resultou desse processo o seguinte: um município formado pela migração "forçada", pelo critério de um Trampolim Demográfico e que possui uma dinâmica socioespacial ambígua e de difícil gestão. 


\section{Referências}

ARRAIS, T. A. A Região como Arena Política. Ensaios Temáticos. Goiânia: Editora Vieira, 2007.

BARREIRA. C. C. M. A. Fragmentação das cidades-regiões na dinâmica espacial goiana: o entorno do DF e Goiânia. Relatório Técnico Final: MCT/CNPq 02/2006 Universal. Universidade Federal de Goiás, Goiânia, 2009.

CARLOS, A. F. A. (Org.). A produção do espaço urbano: Agentes e processos, escalas e desafios. São Paulo: Contexto, 2011.

CHAVEIRO, E. F.; CALAÇA. M. A dinâmica demográfica do Cerrado: o território goiano apropriado e cindido. In: Universo do Cerrado. Goiânia: Ed. UCG, 2008. p. 287-307.

IBGE - Instituto Brasileiro de Geografia e Estatística. Censo/2010.

PAVIANI, A. (Org.). Urbanização e metropolização. Brasília: Ed. UnB, 1987.

PAVIANI, A.; GOUVÊA, L. A. de C. (Orgs.). Brasília: controvérsias ambientais. Brasília: Ed. UnB, 2003.

REIS, G. Imobiliário de Luziânia. Luziânia-GO, 1975.

SANTOS, M. A Urbanização Brasileira. São Paulo: Edusp, 2009.

Eguimar Felício Chaveiro - Doutor em Geografia pela Universidade de São Paulo - Professor da Universidade Federal de Goiás.

Gilmar Elias Rodrigues da Silva - Mestre em Geografia pela Universidade Federal de Goiás - Professor na Secretaria Municipal de Educação de Valparaíso de Goiás. 